\begin{tabular}{|c|l|}
\hline Title & Extraordinary weight gain : initial finding in a patient with peripartum cardiomyopathy \\
\hline Author(s) & Endo, Daisuke; Morikawa, Mamoru; Sakakibara, Mamoru; Sugita, Tsubasa; Y amada, Takahiro; Minakami, Hisanori \\
\hline Citation & $\begin{array}{l}\text { Case Reports in Perinatal Medicine, 3(1), 45-47 } \\
\text { https://doi.org/40.1515/crpm-2013-0052 }\end{array}$ \\
\hline Issue Date & 201406 \\
\hline Doc URL & http://hdl.handle.net/2115/59438 \\
\hline Type & article (author version) \\
\hline File Information & Case Rep Perinat Med_3(1)_45-47.pdf \\
\hline
\end{tabular}

Instructions for use 


\title{
Case Reports in Perinatal Medicine
}

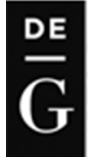

\author{
DE GRUYTER Case Reports in \\ Perinatal Medicine
}

\section{Extraordinary weight gain: initial finding in a patient with peripartum cardiomyopathy}

\begin{tabular}{|r|l|}
\hline Journal: & Case Reports in Perinatal Medicine \\
\hline Manuscript ID: & crpm.2013.0052.R2 \\
\hline Manuscript Type: & Case report \\
\hline Section/Category: & Obstetrics \\
\hline Classifications: & 1310 high-risk pregnancy \\
\hline Keywords: & gestational edema, vascular permeability, weight gain during pregnancy \\
\hline Abstract: & $\begin{array}{l}\text { Extraordinary weight gain may be an initial finding in some patients with } \\
\text { peripartum cardiomyopathy (PPCM). This case highlights the need for } \\
\text { studies of the relationship between degrees of antenatal weight gain and } \\
\text { risk of PPCM. } \\
\text { Case: A 33-year-old woman exhibited weight gain of } 1.0 \mathrm{~kg} / \text { week }(38.5- \\
\text { 60.6 kg) between gestational weeks (GW) } 12-2 / 7 \text { and } 33-2 / 7 \text { at which } \\
\text { dyspnea appeared. Her body weight further increased to } 69.1 \mathrm{~kg} \text { at GW } \\
\text { 34-2/7 at which echocardiography revealed left ventricular dysfunction } \\
\text { (ejection fraction }=27 \% \text {, fractional shortening }=4.0 \% \text { ). She then lost } 24 \\
\text { kg in body weight by 4 weeks postpartum. } \\
\text { Abstract-PPCM-CRPM-Revised.docx }\end{array}$ \\
\hline
\end{tabular}

\section{SCHOLARONE}




\section{Introduction}

Peripartum cardiomyopathy (PPCM) is an idiopathic cardiomyopathy presenting with heart failure (HF) secondary to left ventricular (LV) systolic dysfunction toward the end of pregnancy or in the months following delivery, where no other cause of HF can be found. It is a diagnosis of exclusion. The LV may not be dilated but the ejection fraction (EF) is nearly always reduced below $45 \%$ as proposed by the European Society of Cardiology [7]. The presenting symptoms include dyspnea, orthopnea, tachycardia, and peripheral edema $[1,7]$. However, as edema is common in healthy pregnant women and as PPCM is a rare complication occurring in 1 per 3000 - 4000 women [2], diagnosis of PPCM is often delayed resulting in major adverse events, such as death or heart transplantation [4].

As all of the common presenting symptoms, such as dyspnea, orthopnea, and peripheral edema, suggest excessive water retention in patients with PPCM, extraordinary weight gain may be an initial finding in some patients with PPCM. However, it has not been well documented whether excessive weight gain actually precedes the onset of PPCM. This case presentation was conducted with the approval of the institutional review board of Hokkaido University Hospital.

\section{Case Presentation}

A 33-year-old Japanese woman at gestational week (GW) $34^{-2 / 7}$ of pregnancy was referred to our hospital due to dyspnea and orthopnea. Her dyspnea began at GW $33^{-2 / 7}$ and she visited a local hospital at GW $34^{-0 / 7}$, but declined hospitalization despite the referring physician's strong recommendation. She visited the local hospital again two 
days later due to worsening of dyspnea and was transported to our hospital. She had history of one prior birth of a healthy male infant 4 years before the current pregnancy and treatment for depression and eating disorder. As she believed that depression and eating disorder disappeared, she did not take any medicine for these disorders in the current pregnancy. The results of physical examinations were as follows: body temperature of $36.4^{\circ} \mathrm{C}$, body height of $1.48 \mathrm{~m}$, body weight of $69.1 \mathrm{~kg}$, blood pressure of 95/67 mmHg with sinus tachycardia of $120 \mathrm{bpm}$, proteinuria (1+ on dipstick test, 42 $\mathrm{mg} / \mathrm{dL}$ of protein, and $117 \mathrm{mg} / \mathrm{dL}$ of creatinine in spot urine) and marked generalized edema (pitting edema was detected at antenatal cares given at GW $31^{-2 / 7}, 33^{-2 / 7}$, and $34^{-0 / 7}$ ). Cardiomegaly with an enhanced vascular shadow and pleural effusion by chest X-ray (cardiothoracic dimension ratio [CTR】 of 63\%), left ventricular dysfunction by echocardiography (ejection fraction [EF], 27\%; fractional shortening [FS], 4.0\%), and blood BNP of 2024 pg/mL suggested PPCM. However, the SpO2 was 99\% under room air. The patient gave birth to an otherwise healthy premature male infant weighing 2576 $\mathrm{g}$ by cesarean section $3 \mathrm{~h}$ after admission and was admitted to the ICU. Liver dysfunction and hyponatremia (AST/AST, 126/93 IU/L; Na, 120mEq/L on admission) improved soon after delivery, but cardiac dysfunction persisted (EF, 22\%; FS, $8.0 \%$ on postpartum day 39). Diuretics including furosemide and atrial natriuretic peptide were used aggressively after delivery. The patient left hospital on postpartum day 61. The cardiac function improved markedly showing CTR of 40\%, EF of 39\%, and FS of

\section{$20 \%$ on postpartum month 9.}

Extraordinary weight gain preceded PPCM in this patient (Fig. 1); her body weight of $38.5 \mathrm{~kg}$ at $\mathrm{GW} 12^{-2 / 7}$ increased to $57.5 \mathrm{~kg}$ at $\mathrm{GW} 31^{-2 / 7}, 60.6 \mathrm{~kg}$ at $\mathrm{GW} 33^{-2 / 7}, 64.3 \mathrm{~kg}$ at GW $34^{-0 / 7}$, and $69.1 \mathrm{~kg}$ on the day of delivery at GW $34^{-2 / 7}$. Her body weight then 
decreased to $45.2 \mathrm{~kg}$ and $37.4 \mathrm{~kg}$ on postpartum day 27 and postpartum month 9. respectively.

\section{Discussion}

This patient exhibited an extreme change in the body weight during pregnancy and postpartum: weight gain was approximately $1.0 \mathrm{~kg} /$ week $(22.1 \mathrm{~kg} / 21$ weeks $)$ during 19 weeks between GW 12 and 33, $8.5 \mathrm{~kg}$ during the last antenatal one week (4.8 $\mathrm{kg}$ in the last antenatal two days). Thus, this lean woman (body mass index of $17.6 \mathrm{~kg} / \mathrm{m}^{2}$ at $\mathrm{GW}$ 12) gained more than $30 \mathrm{~kg}$ of body weight at and after GW 12, suggesting that extraordinary excessive water retention had occurred, especially in the late stage of pregnancy, leading to cardiac overload. The $97.5^{\text {th }}$ percentile value for weight gain during the last antenatal two weeks is $4.0 \mathrm{~kg}$ and that for weight loss during the postpartum 1 month is $13.1 \mathrm{~kg}$ in 272 healthy Japanese women [8], while this patient exhibited a weight gain of $8.5 \mathrm{~kg}$ during the last antenatal one week and lost her body weight by $24 \mathrm{~kg}$ during 4 weeks postpartum. Thus, majority of the $24 \mathrm{~kg}$ lost during 4 weeks postpartum may have been excessively retained water in the late stage of pregnancy in this patient.

Among 128838 women with singleton pregnancies who were registered with the Japan Society of Obstetrics and Gynecology Successive Pregnancy Birth Registry System (this system was described previously [9]), 1404 (1.1\%), 259 (0.20\%), and $72(0.056 \%)$ women exhibited weight gain during pregnancy of more than $20 \mathrm{~kg}, 25 \mathrm{~kg}$, and $30 \mathrm{~kg}$, respectively (corresponding author of this report, Morikawa M. et al., in preparation). Thus, weight gain of more than $30 \mathrm{~kg}$ during pregnancy seen in our case 
seldom occurs in Japanese women. We speculate that such women with extreme antenatal weight gain are at higher risk of developing PPCM based on our case. Our speculation was consistent with results of previous studies that a greater weight gain in pregnancy is associated with the development of preeclampsia [10] and women with preeclampsia are at higher risk of developing PPCM [1,2,3,4,5].

As maternal mortality ranges from $4 \%$ to $15 \%[2,3,5,6]$ and baseline cardiac function at the time of PPCM diagnosis can predict outcome $[1,3,4,5]$, increased awareness of PPCM is required for early diagnosis and aggressive therapy in an attempt to prevent complications [4]. Currently known risk factors for PPCM include hypertensive disorders, multifetal pregnancies, and prolonged use of tocolysis [1,2,3,4,5], and do not include excessive antenatal weight gain, perhaps due to a lack of studies dealing with the relationship between the degree of antenatal weight gain and PPCM. We were not able to access reports that focused on the association between maternal weight gain and the development of PPCM. Thus, to our knowledge, this case report was first one that documented an extraordinary weight gain during pregnancy in a patient with PPCM. If evidence had been available that antenatal weight gain above a certain cut-off level is a risk factor for PPCM, an earlier examination by echocardiography would have been possible and we may have found a modestly depressed but better cardiac function than that seen at GW $34^{-2 / 7}$ in our case. This case highlighted the need for studies addressing the relationship between degree of antenatal weight gain and the risk of developing PPCM.

\section{Conflict of interest}


All authors declare that they have no financial relationships with biotechnology manufacturers, pharmaceutical companies, or other commercial entities with an interest in the subject matter or materials discussed in this manuscript. 


\section{References}

1. Chapa JB, Heiberger HB, Weinert L, Jeanne DeCara J, Lang RM, Hibbard JU. Prognostic value of echocardiography in peripartum cardiomyopathy. Obstet Gynecol 2005; 105: 1303-1308.

2. Carlin AJ, Alfirevic Z, Gyte GML. Interventions for treating peripartum cardiomyopathy to improve outcomes for women and babies. Cochrane Database of Systematic Reviews 2010, Issue 9. Art. No.: CD008589. DOI: 10.1002/14651858.CD008589.pub2.

3. Elkayam U, Akhter MW, Singh H, Khan S, Bitar F, Hameed A, Shotan A. Pregnancy-associated cardiomyopathy: clinical characteristics and a comparison between early and late presentation. Circulation. 2005; 111: 2050-2055.

4. Goland S, Modi K, Bitar F, Janmohamed M, Mirocha JM, Czer LSC, Illum S, Hatamizadeh P, Elkayam U. Clinical profile and predictors of complications in peripartum cardiomyopathy J Cardiac Fail 2009; 15: 645-650.

5. Kamiya CA, Kitakaze M, Ishibashi-Ueda H, Nakatani S, Murohara T, MD, Tomoike H, Ikeda T. Different characteristics of peripartum cardiomyopathy between patients complicated with and without hypertensive disorders - results from the Japanese nationwide survey of peripartum cardiomyopathy -. Circ J 2011; 75: $1975-1981$.

6. Sliwa K, Forster O, Libhaber E, Fett JD, Sundstrom JB, Hilfiker-Kleiner D, Ansari AA. Peripartum cardiomyopathy: inflammatory markers as predictors of outcome in 100 prospectively studied patients. Eur Heart J 2006; 27: 441-446.

7. Sliwa K, Hilfiker-Kleiner D, Petrie MC, et al. Current state of knowledge on aetiology, diagnosis, management, and therapy of peripartum cardiomyopathy: a 
position statement from the Heart Failure Association of the European Society of Cardiology Working Group on peripartum cardiomyopathy. Eur J Heart Fail 2010; 12: 767-778.

8. Yamada T, Kuwata T, Matsuda H, Deguchi K, Morikawa M, Yamada T, Furuya K, Matsubara S, Minakami H. Risk factors of eclampsia other than hypertension: pregnancy-induced antithrombin deficiency and extraordinary weight gain. Hypertens Preg 2012; 31: 268-277.

9. Morikawa M, Yamada T, Yamada T, Sato S, Cho K, Minakami H. Prevalence of hyperglycemia during pregnancy according to maternal age and pre-pregnancy body mass index in Japan, 2007-2009. Int J Gynecol Obstet 2012; 118: 198-201.

10. Morikawa M, Yamada T, Yamada T, Sato S, Cho K, Minakami H. Effect of nulliparity, maternal age, and pre-pregnancy body mass index on the development of gestational hypertension and preeclampsia. Hypertens Res Preg, in press

\section{Figure legend}

\section{Fig. 1: Perinatal changes in body weight in this patient with peripartum}

\section{cardiomyopathy}

The shaded area indicates the range of the $2.5^{\text {th }}-97.5^{\text {th }}$ percentile value obtained from 272 control women with neither hypertension nor pregnancy-induced antithrombin deficiency [8]. 


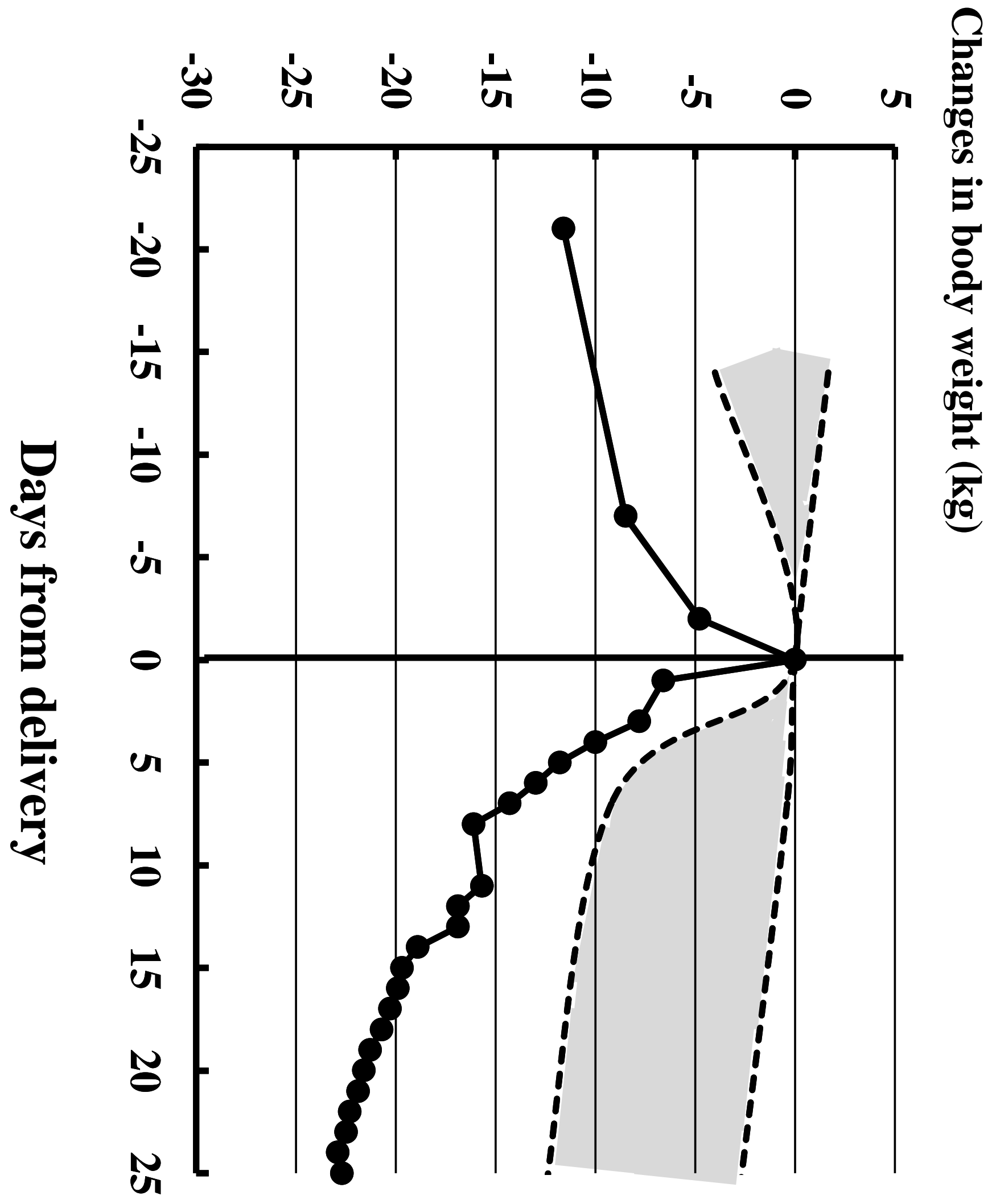

